\title{
Spontaneous Enterocutaneous Fistula: A Rare Presentation of Incarcerated Femoral Hernia
}

\author{
Meriç Emre Bostancı, İlker Özel, Birkan Bozkurt, Sinan Soylu, Mustafa Turan \\ Department of General Surgery, Cumhuriyet University Faculty of Medicine, Sivas, Turkey
}

\begin{abstract}
Although femoral hernias are less commonly seen compared with other types of hernias, they have an inversely proportional importance to its lower frequency because of its higher risk of strangulation, morbidity, and mortality. In neglected cases, strangulation may cause enterocutaneous fistula; as a result, a mortal clinic with electrolyte imbalance, anemia, and malnutrition can be seen. This clinical condition requires immediate surgical intervention. Because this is a rare clinical presentation, we have reported a neglected case of femoral hernia in a 75-year-old woman admitted to our emergency department with an enterocutaneous fistula secondary to intestinal strangulation. (Eurasian J Emerg Med 2015; 14: 199-200)
\end{abstract}

Keywords: Femoral hernia, strangulation, spontaneously, enterocutaneous fistula

\section{Introduction}

The most common type of hernia appearing in the inguinal region is indirect inguinal hernia (1). The swelling occurring below the inguinal ligament is suggestive of femoral hernia. This type of hernia most frequently occurs in females and constitutes $11 \%$ of all hernia cases in them (2). Although the incidence of femoral hernias is rare as compared with that of external abdominal hernias, the likelihood of strangulation is higher because of the fact that the hernia orifice is narrow (3). Despite the fact that enterocutaneous fistula formation that occurs in strangulated cases is a rare complication, it might still occur in delayed and neglected cases (4). The incidence of such cases is closely related with factors such as late hospital visit, low socioeconomic status, lack of specialists, and negligence. Patients with this rare complication might appear to be anemic, dehydrated, and malnourished septic picture and may even present with peritonitis (5). The treatment of such cases requires a definitive surgery including procedures such as correcting fluid electrolyte imbalance and performing blood transfusion in necessary cases, antibiotherapy, small bowel resection, anastomosis, and femoral herniography as well as providing nutritional support.

\section{Case Presentation}

A 75-year-old female patient with swelling on her right inguinal region accompanied with stinking discharge in the swollen part and pain was admitted to the emergency department, and her case was consulted. On examination, the patient had swelling in her inguinal region since the last 1 week, and she showed sensitivity in the abdomen, minimal abdominal distention, and incarcerated femoral hernia on her right inguinal region. Intestinal content was discharged through the fistula orifice that was $3 \mathrm{~cm}$ in diameter (Figures 1a, b). It was observed that the skin tissue surrounding the fistula orifice was necrotizing. The history of the patient did not indicate anything beyond diabetes mellitus and hypertension. Abdominal tomography of the patient was reported to be a small bowel segment herniated on the inguinal region passing through the femoral channel, and small bowel loop was fistulized to the skin (Figure 2). The patient had a pulse of $130 / \mathrm{min}$, blood pressure of $70 / 40$ $\mathrm{mmHg}$, fever of $39.1^{\circ} \mathrm{C}$, and breathing rate of $32 / \mathrm{min}$. In routine blood test, her hemoglobin level was $8.1 \mathrm{~g} / \mathrm{dL}$, leucocyte count was $17600 / \mu \mathrm{L}$, and CRP level was $158(0-8) \mathrm{mg} / \mathrm{L}$. The patient was cachectic, and her overall condition was bad. Because the patient had septic findings, she was hospitalized in our service room after obtaining her consent on the same day of admission in the emergency department. Blood transfusion was given to the patient, and administration of broad spectrum antibiotics was started. An urgent laparotomy was planned for the patient, but she died before the operation because of her overall bad condition.

\section{Discussion}

Although femoral hernias are rare as compared with external abdominal hernias, the likelihood of strangulation is higher because of

Correspondence to: Birkan Bozkurt e-mail: birkan.bozkurt@gmail.com

Received: 22.12.2014 Accepted: 08.01.2015

(C) Copyright 2015 by Emergency Physicians Association of Turkey - Available online at www.eajem.com DOI: 10.5152/eajem.2015.65807 


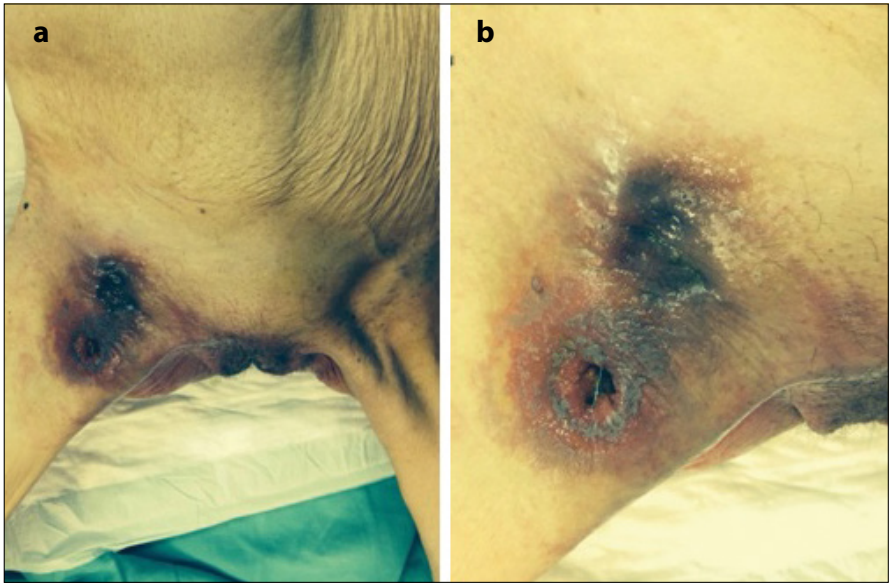

Figure 1. a, b. Enterocutaneous fistula orifice associated with incarcerated femoral hernia

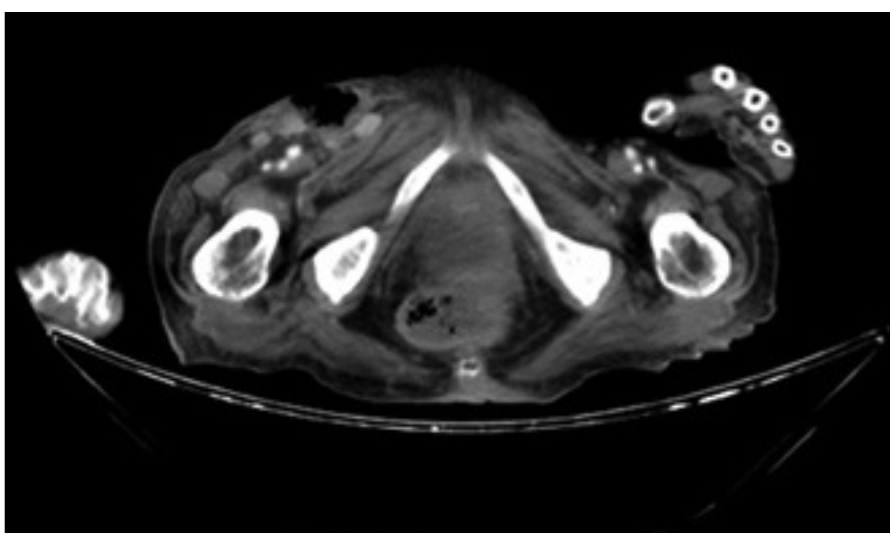

Figure 2. Small bowel segment herniated on the femoral channel in abdominal tomography

the narrow hernial orifice (3). Even though enterocutaneous fistula formation developing in strangulated cases is a rare complication, it might occur in delayed and neglected cases (4). The incidence of hernia complications in developing countries is increasing as a result of low socioeconomic status, lack of specialists, and negligence as in the case of other diseases and complications. Herniated bowel loops fistulized to the skin, as that found in our patient, is a rare complication reported in extremely few number of cases in the literature. Moreover, in the present case, it is thought that the hernia present for years occasionally caused obstruction signs, but these signs re- gressed after fistula formation; this could be due to visiting the hospital later than required.

Enterocutaneous fistulas are associated with high morbidity and mortality. Sepsis, malnutrition, and fluid electrolyte imbalance are the most important determinants of mortality in patients who develop enterocutaneous fistula along with incarcerated femoral hernia (5-7).

\section{Conclusion}

Incidence of enterocutaneous fistula along with incarcerated femoral hernia is directly associated with late hospital visit, low socioeconomic status, lack of specialists, and negligence. In delayed cases, clinical conditions such as electrolyte imbalance, anemia, and malnutrition disturb the overall condition of the patient, resulting in a life-threatening situation. The treatment requires definitive surgical intervention following resuscitation.

Informed Consent: Written informed consent was obtained from patient who participated in this case.

Peer-review: Externally peer-reviewed.

Conflict of Interest: No conflict of interest was declared by the authors.

Financial Disclosure: The authors declared that this study has received no financial support.

\section{References}

1. Rutkow IM. Epidemiologic, economic, and sociologic aspects of hernia surgery in the United States in the 1990s. Surg Clin North Am 1998; 78 : 941. [CrossRef]

2. Iten LL, Infectien in inguinal hernia repair considering bromaterials and antibiotics. Surg Gynecol Obstet 1993; 177: 126-30.

3. David T. Strangulated femoral hernia. Med J 1967; 1: 258.

4. Ihedioha U, Alani A, Modak P, Chong P, O'Dwyer PJ. Hernia are the most common cause of strangulation in patients presenting with small bowel obstruction. Hernia 2006; 10: 338-40. [CrossRef]

5. Taggarshe D, Bakston D, Jacobs M, Mckendrick A, Mittal VK. Management of enterocutaneous fistulae: A 10 year experience. World J Gastrointest Surg 2010; 2: 242-56. [CrossRef]

6. Joyce M, Dietz D. Management of complex gastrointestinal fistula. Curr Prob Surg 2009; 246: 379. [CrossRef]

7. Datta V, Windo AC. Surgical Management of enterocutaneous fistula. Br J Hosp Med 2007; 68: 28-31. [CrossRef] 